\title{
Implementing School Management in the Arab Palestinian Education System in Jerusalem Schools, the Viewpoint of the Administrative Staff
}

\author{
Omar Mizel
}

Correspondence: Omar Mizel, Associate professor, Bethlehem University, Jerusalem.

Received: February 26, 2018

doi:10.11114/jets.v6i11.3617
Accepted: September 9, $2018 \quad$ Online Published: September 12, 2018

URL: https://doi.org/10.11114/jets.v6i11.3617

\begin{abstract}
This study aims to examine the impact of School-Based Management (SBM) on Arab Palestinian schools in East Jerusalem. SBM, which has become a major and irreversible trend in educational reform in Western countries, has been introduced into a number of Asian and African nations over the last few decades. Consequently, a higher level of autonomy and decentralization constitutes the "default" approach to the management of schools within centrally-determined policies, goals, standards, curriculum, and accountability. However, the literature on SBM does not address the repercussions of implementing SBM in conflict zones such as Palestine in the context of larger political questions about power and ideological control. Using a qualitative methodology, field observations, and in-depth interviews with a sample of various stakeholders in Arab-Palestinian schools in East Jerusalem, including school principals and faculty members, this study investigates the impact of SBM on the educational system in these schools, their philosophy, policies, objectives, and the implementation of the curriculum, and the consequences of this on designing a "programmed" educational system educational outputs and learning outcomes. Findings show that these school reforms are driven not by a commitment to decentralization but by political and or ideological considerations (Israelifications and the assimilation of Palestinians within Israeli educational and philosophical frameworks). The study recommends that leaders in the field of education and education and local authorities in the Palestinian Arab community take appropriate measures to correct the current trajectories of the educational process in East Jerusalem schools.
\end{abstract}

Keywords: SBM, Jerusalem, staff, Israel, Palestine

\section{Introduction}

\subsection{The Arab Education System in Israel}

The Palestinian Arab population in Israel amounts to 1.7146 million, 20.2\% of the total population, and includes Muslims (1.4203 million), Christians (160.9 thousand) and Druze (133.4 thousand) (Office Central Statistics Office, 2015). The Arab population resides mainly in separate communities, in rural regions affected by economic scarcity, with the exception of some mixed cities. It is a heterogeneous society and consists of a variety of cultures, religions, ideologies and geographical areas. In addition, the Arab population differs from the Jewish population in culture, norms, and values, and is influenced by the norms and values of neighboring countries.

The Jewish and Arab educational systems are separated and unequal resources are invested in them. Literature has dealt extensively with the discrimination of Arab education by Israeli educational systems. The Statistical Yearbook of the Taub Institute (2014) indicates that in 2012, the percentage of students eligible for enrollment in the Hebrew education system was $73.6 \%$ vs. $50.7 \%$ in the Arab education system. As a result, the Arab educational system suffers from lower physical infrastructures, formal budget inequality, fewer school hours allocated to the class or student, quality of teaching staff, quality of support services and, as a result, lower outcomes. (Author, 2009, 2012, 2016)

Therefore, it is expected that the education system will adopt a policy that ensures essential equality in case of low starting points for certain social groups, as do other populations in the country.

\subsection{The Education System in East Jerusalem}

The education sector in East Jerusalem is that it is not supervised and governed by one body. There is no single authority that is responsible for the implementation of public education policy and is responsible for any deficiencies in the education sector.

Just as there is a political conflict over the sovereignty of the city, there is a conflict over who takes over the education 
sector. The triad of public education (consumption, government, a period of service) (Besley and Ghatak, 2003) is dysfunctional in East Jerusalem. There are four different triads. The first triad consists of the Palestinian consumer, the Israeli government and Manchi as a service provider; the second triad consists of the Palestinian consumer, the Palestinian Authority and the Jerusalem Education Directorate as a service provider (Awqaf School), and the third triad is the Palestinian consumer, the United Nations and the United Nations Relief and (UNRWA), which is a system of schools. Educational provision is also provided by private schools, which are not governed by a supervisory body. It could be assumed that because there are several service providers, there will be a wide range of services. By contrast, according to the 2009 State Comptroller's Report, there was a shortage of more than 1,000 classrooms in East Jerusalem (Nusibeh, 2013). This shortage has led to overpopulation in existing schools, in all systems including private schools, with a slight variation between systems.

\subsection{The Four Different Supervising Bodies}

1. Manchi-The Jerusalem Education Administration. The joint body of the Israeli Municipality of Jerusalem and the Israeli Ministry of Education.

2. Awqaf or Muslim Endowment, in collaboration with the Palestinian Ministry of Education, but the latter is prohibited from operating in Jerusalem in accordance with the Oslo Accords, so these schools are governed by the Palestinian Education Directorate of Jerusalem. They are called Awqaf schools.

3. The United Nations Relief and Works Agency (UNRWA), which oversees primary and elementary schools for Palestinian refugees.

4. Local charities and other private schools.

Table 1. Supervising bodies of the education sector in East Jerusalem (2012/2013)

\begin{tabular}{l|r|r|r}
\hline \multicolumn{1}{c|}{ Supervising Body } & $\begin{array}{c}\text { No. of } \\
\text { schools }\end{array}$ & No. of students & $\begin{array}{c}\text { Percentage of } \\
\text { students }\end{array}$ \\
\hline Manchi- Municipal Schools serving Palestinian Students & 57 & 42.271 & $47 \%$ \\
\hline Awqaf Schools & 38 & 12.400 & $14 \%$ \\
\hline UNRWA schools & 8 & 2.442 & $3 \%$ \\
\hline Local charities and other private schools & 82 & 28.842 & $31 \%$ \\
\hline Students not registered in any system & & 4.387 & $5 \%$ \\
\hline Total & 181 & 90.324 & $100 \%$ \\
\hline
\end{tabular}

Source: This table was created by a compilation of data from the Education Directorate of Jerusalem Palestine and the Jerusalem Education Administration of Israel (Manchi, 2012).

Three systems in East Jerusalem offer free education to Palestinian students; Israeli-controlled municipal schools, Palestine-controlled Awqaf and UNRWA seek to fill gaps in municipal provisions. However, they do not have full control over their schools in Jerusalem and are not recognized by the Israeli Municipality. There is no cooperation between the Israeli municipal system and the other two systems, which means that it is difficult to measure how many children are cared for who, where and how well.

According to the Israeli Ministry of Education, Manchi is the official provider of education services in East Jerusalem and the other systems controlled by Awqaf and UNRWA are considered unofficial. The Israeli Ministry has two categories for private schools. Schools that meet their standards, are supported by grants and are considered recognized but not official, while private schools that refuse to work with the municipality and respect its rules are considered unrecognized and unofficial. The opposite applies to the Palestinian Ministry of Education. The Palestinian Ministry of Education considers Awqaf schools as the official provider of education in East Jerusalem, regardless of whether or not they are subsidized by the Israeli government. However, the Palestinian Ministry does not financially support private schools because of its limited budget; only supports Awqaf schools. The Palestinian Ministry of Education does not recognize Israeli municipal schools that provide education to Palestinian students and do not cooperate with them.

In the current political situation, Israel is controlling East Jerusalem and such a strong education system in the city is the Israeli system. This system provides education to a greater number of students; is connected to the social service, the ministry of the interior and the police. It also enjoys higher budgets and has recently expanded to subsidies and control of private schools in Jerusalem. On the other hand, the Palestinian Ministry of Education provides education to $14 \%$ of the student population of Jerusalem. It does not have full control of its school buildings because those buildings are located in Jerusalem, which is under Israeli control, so Palestinian schools can not renovate school buildings or extend those buildings without Israel's permission. The provision of educational services and struggles between the Palestinian Authority and the Israeli Municipality is a mirror of the political conflict over the city. (Nusibeh, 2013) 


\subsection{SBM in the Israeli School System}

Educational policy in Israel is set by the Ministry of Education. From its inception, the Israeli educational system has had a centralised management structure, as this was deemed the most effective means of assuring education of equal quality in all schools. All staff, from administrators to teachers and educational counsellors, are employees of the Ministry, and there is a single salary schedule based on the level of education and years of experience.

A distinct feature of the Israeli educational system is the official segregation between institutions for Jews and those for Arabs. There are instances, however, where Arabs who live in mixed urban areas attend Jewish schools, and there are now five Jewish-Arab elementary schools in the country. There is a further subdivision in the Jewish educational system into a state religious and a secular system. Additionally, a fairly large number of schools in both the Arab and the Jewish systems are private, but they are recognised and funded in large part by the government. School budgets and teaching hours are not equally distributed between these many parallel systems. It has been estimated that most Jewish elementary schools receive over 25\% more resources than Arab schools; in the secondary schools, this disparity is even higher (Rabin, 2002). The student: teacher ratio in Arab elementary schools is higher than that in Jewish elementary schools (i.e. there are more students per teacher in this sector), and this increases further in the junior and high school years. Furthermore, the kinds of educational programmes offered are not equal. For example, while $60 \%$ of Jewish high school students are enrolled in vocational/technological courses of study, this is true for only $20 \%$ of Arab students.

Moreover, the vocational courses offered in the Arab schools are generally at a low level (i.e. not pre-college academic tracks) and do not lead to matriculation (Rabin, 2002; Swirski \& Huri, 1997). Recently, the Israeli Ministry of Education has begun investing more resources (including funds) in the Arab educational system, and some improvement in national test scores and numbers of high school graduates achieving matriculation has been noted (Author, 2005, 2015, 2016).

The concept of self-management in education was first raised in Israel in 1992, but it did not arise in a vacuum. In fact, the idea was raised because of the long-term power struggle between the central government and the regional governing councils for control over the schools. Additionally, increasing awareness of educational reforms worldwide brought the Ministry of Education to a recognition that it was in its interest to promote self-governance in schools. This trend increased in momentum as the result of two primary factors: first, there was a growing acknowledgement that the supervisory mechanisms were not succeeding in overseeing the educational processes undertaken by the schools (Gaziel, 2003), and second, educators began to sense that centralised management was reducing the ability of schools to respond appropriately and in a timely way to the many changing circumstances they faced (Vollansky \& Bar-Eli, 1995).

Accordingly, in 1992, the Minster of Education appointed a steering committee to examine options for increasing autonomy in schools. The committee recommended implementing SBM in the Israeli school system but with some caveats. Specifically, each school would be required to determine clear goals, develop learning plans and set up a board of directors. Government educational allotments would be transferred to SBM schools via the local authorities and these schools would also be entitled to raise funds from non-public sources through a non-profit association (known as an amuta in Hebrew) that would act in accordance with the standards and procedures set by the Ministry of Education. Donations acquired thus are to be utilised for educational programmes and activities for the benefit of all students, without discrimination or preference of any kind. Moreover, it was recommended that the tax-exemption limit be raised to encourage individuals and entities to make donations to schools. While the goal of the transition to SBM was to increase school autonomy, ironically schools are not given the freedom to decide whether they wish to take part in this process - the Ministry of Education alone determines which schools are to be conducted according to SBM. Schools cannot request to be included in this programme, and while the initiative from the Ministry is in the form of a request, not a requirement, it has never happened that a school has formally refused this request. Regarding the Arab-Bedouin sector, the Ministry of Education was not satisfied with the poor educational outcomes in this sector and hoped that SBM would improve this situation (Author, 2005, 2012, 2016).

The impact of this policy was investigated in a study by Gaziel, Bogler, and Nir (2005), which reviewed the implementation of self-governance Israeli public schools representing a cross section of the ethnic groups in the nation. In the study, secular Jewish schools in small communities, religious Jewish schools in small communities, Arab schools in a large city, Druze schools (in small Druze communities) and regional secular Jewish schools were included. Forty-four schools in the first year since designation as SBM schools were compared with 109 schools that had been functioning as SBM schools for 3 years. The study concluded that teachers, in both newly designated and veteran SBM schools, did not have a clear understanding of the implications of SBM as a tool for budgetary management, nor did they have a coherent understanding of the concept of SBM as an educational system, in general. Moreover, this research determined that de facto the Israeli educational system remains centralised, although 'on paper, there is a clear policy of decentralisation and transitioning to an SBM model throughout the country (in both Arab and Jewish tracks). 
Two other Israeli research studies by Friedman, Barma, and Toren (1997) and Nir (2001), respectively, have independently investigated the implementation of SBM in Israel and reached contradictory conclusions. Friedman et al. (1997) studied 13 Jewish schools in Jerusalem during the beginning of their transition to SBM. They interviewed the principals, observed classes, analysed questionnaires distributed to both teachers and principals, and reviewed the schools' curricula. The conclusion that they drew supported the view that decentralisation was intimately related to the implementation of SBM and its various benefits: greater accountability, teamwork and curriculum development. Nir (2001) conducted a quality study of all 28 of the Jewish SBM schools in Jerusalem at that time (10 religious and 18 secular), examining their organisational structure and the curricula, as well as the teachers' commitments to their profession and to their students. Based on this, Nir concluded that decentralisation does not necessarily lead to the outcomes credited to SBM and states that each component of the SBM model - accountability, teamwork, improved educational outcomes, etc. - must be evaluated individually, and only then can a connection between decentralisation and SBM be determined. (Author 2005)

\subsection{SBM at Arab Palestinian Schools in Israel}

One of the most significant approaches taken to achieve this goal is school-based management.

The world is witnessing numerous challenges that directly influence educational goals and curricula. On the other hand, the growing changes in this century, reflected in the growing information and technology revolution, have led to the development of education and its institutions to be the first priority in developing countries. The development and organization of the educational process require numerous changes and reforms in the education system. One of the new trends to this effect is to grant more freedom to schools in terms of decision making to achieve an improvement in the educational process.

The assumptions that led to the self-management of schools in the world and in Israel are the same ones that led to self-management in Arab society in the city of Jerusalem. At the same time, East Jerusalem society has different characteristics, since it is basically political; the traditional veterinarian is exposed to various influences.

Since the start of the project, this research has been carried out to examine the scope of application of the three basic components of this study on the Israeli model (decision making, budget, and curriculum).

\subsection{Decision Making}

Many scholars stressed that the decision-making mechanism is one of the essential components of the SBM. The Ministry of Education empowers principals and school personnel to conduct school operations. (Fridman, 2003, Caldwell, 2012) indicated that the mechanism and freedom of decision-making lead to the construction of a system of accountability and evaluation of learning outcomes, as well as a diversion of bureaucracy that positively reflects the efficient functioning of the school.

On the other hand, (Auhtor, 2012) (Said, 2008) the study indicated that the success of decentralization depends on having an evaluation matrix that regulates this project. For example, before the implementation of the project, democracy, the culture of dialogue, the new methodology of teaching and working in a team should be adopted. The absence of such bases in traditional and developing societies could constitute an obstacle to the implementation of this project. In addition, the complex situation of Jerusalem schools, which are under occupation, greatly complicates the implementation of this component. Following the Palestinian curriculum on the one hand and the management of the financial and organizational affairs of the school by the Israeli Ministry of Education, on the other hand, it creates a vague situation with regard to the decision-making mechanism that will undoubtedly have an effect on the process of project implementation.

\section{Curriculum}

Several studies in Australia and the United Kingdom (Caldwell, 2012 and Cheng, 2000) indicated that this component is considered a basic component in SBM as it allows the school to build plans and curricula that meet the needs of schools. (Author, 2005) studies indicated that SBM as part of having teams to build teaching units can encourage critical and innovative thinking. The development of the curriculum will contribute to the formation of work teams to advance and achieve accomplishments; therefore, the critical and innovative thinking of teachers will be developed, as well as the development of a team spirit that will be reflected positively in the improvement of the educational process. On the other hand, (Shuvelson, 1987) and Emmanuel, 1996), as well as the State Comptroller's report in Israel (2008) indicated the inability of teachers to draw up teaching plans since this requires advanced skills and potentials teachers are often lacking. This was underlined by (Author, 2011) study on Arab schools. Weaknesses were revealed in the skills and abilities of teachers in the creation of teaching plans; in addition, such a task consumes a lot of time on the part of the teachers who are already busy. In addition, sensitivity to the Arab minority by the Ministry of Education is another obstacle. The Ministry reviews and censors the curriculum for fear of including curriculum content in nationalist and patriotic content, against Israeli interests. 
The situation in the schools of Jerusalem in this sense is more complex than at local and international level. Educational materials in Jerusalem are subject to the Palestinian educational system. Different reports said that the contents of the Palestinian curriculum are instigating, so they have to be eliminated. As a result, the Municipality of Jerusalem and the Ministry of Education censure revise and inspect textbooks and curricula and make modifications or deletions of unwanted content. This process takes a long time causing a delay in the delivery of textbooks to schools; in addition, modifications or deletions cost the state budget 3 million shekels according to the Kensett Research Committee (Knesset Research and Information Center, 2010).

The question is again how this situation is in harmony with the principle of SBM that underlines freedom in the preparation of the curriculum of teaching.

\subsection{Financial Aspect of SBM}

The common Israeli model of SBM is "the financial model" that prepares the way for the school to leave the bureaucracy and gives the principal and the school the authority to allocate budgets according to the needs of the school based on the decision of the principal (Gazil, 2003).

The Israeli model allows the school to obtain funds from three different sources, namely the Ministry of Education, Municipality and External Sources.

(Gazil, Boglar, Nir, 2005), studies indicate that the Israeli model does not assign to the school a budget according to the number of classes but according to the number of students. The budget has to be transparent and the same among all schools. Therefore, there is a kind of flexibility in spending and operating the budget according to the needs of the school.

The problem lies in the third source, which is external financing. For our research, Arab schools lack external funds, as opposed to Jewish schools with interested parties and institutions in different countries of the world, and these constitute a substantial source of funding.

The Palestinian community mentioned above is a complex society under occupation. It suffers from severe levels of poverty, making it difficult for a school to raise funds from parents or external sources. The fear and excessive sensitivity of raising funds with external resources, which the Ministry of Education considers opponents, will obstruct and stifle the school's ability to raise funds. Thus, the gap between strong schools capable of raising funds and schools incapable or prohibited to raise funds will become wider (Author, 2005).

This could negatively affect the SBM in schools in Jerusalem, especially in light of the poor infrastructure of these schools. They need rehabilitation and rehabilitation, but the resources of SBM assigned to them by the Ministry are not enough.

\section{Methodology}

\subsection{Research Questions}

Several questions were asked and the main questions were intended to identify how members of the administrative staff see SBM. Other secondary questions related to SBM in specific areas were asked.

1. How do SBM staff describe in general?

2. How does the SBM describe the administrative staff with respect to educational programs?

3. How does the administrative describe the SBM in the financial aspects?

\subsection{Research Methodology}

The basic aim of the study was to determine the degree to which SBM and its corollary of school based curriculum, financial aspects of SBM. Decision making, are implemented in the sector studies.

\subsection{School and Participants}

The study consisted of interviews with 25 members of five schools that were among the first schools in which the SBM project was implemented in East Jerusalem (5 head teachers and 20 administrative staff). They attended an SBM workshop and previously attended leadership and management courses with the researcher.)

All staff from Jerusalem and not holding Israeli passport and living under the Israeli occupation.

\subsection{Instruments and Interview}

A semi structured interview, which was conducted with all 25 members and focusing group. 


\subsection{Data Collection Procedures}

The interviews with the members were conducted during the workshop lead by the researcher, as mentioned before, the researcher used semi structure interview. He asked them to describe in writing how they see SBM, the researcher maintained a focus group for two hours participants responses were recorded and documented. For example, a discussion of topics in the focus group included, How decisions are made, how the school budget is prepared and spent, and the ability to build teaching plans. These are general issues in which SBM is not mentioned in order to avoid any subjectivity. The organization's counselor was also interviewed for two hours during which questions were asked about the SBM.

The information provided by the organizational counselor can add to what the administrative staff members mentioned. It was also intended to examine the degree of overlap between its views and those of administrative staff.

\section{Data Analysis}

The research used in the study the method of content analysis; this analytical approach depends on an examination and a detailed study of the information and a detailed study of the information given by the participants to arrive at the main aspects that are related to essential topics discussed in the interviews and the focus group.

Difficulties faced by the researcher:

- It is qualitative research, so it's difficult to generalize results since the sample is small.

- Since implementation of the project is in it's early stages, it is difficult to infer the effectiveness level of the program (Caldwell 2006)

- The investigation depends on the opinion of the administrative staff without indicating the actual practice in the school. However, and regardless of the above, the way of the team of administrative staff sees the SBM project reveals significant points of view and issues that cannot be overload in practice and these can be of benefit later on.

Qualitative Finding

Interview respondent replied to the specific questions asked and, as noted above, were invited to expand upon or add to their replies.

A representative sampling of what respondents said about school based management and their explanation for why if did not exist in their schools is given below.

\section{Findings}

The results were presented according to the research questions, as indicated in the methodology starting with the main question. This chapter will not document all the answers, but it cites points of view.

\section{How do teachers describe SBM in general?}

\section{- Conflict between Government Policy and Schools}

20/25 indicated that SBM gave them a good feeling because they would independently manage their schools by themselves. This view was common immediately after the end of the course. However, during in-depth interviews, it became clear that this satisfaction was in the emotional rather than in the real life. For example, one staff member said, "Participation in the project was at the request of the department and the municipality. In fact, this requires questions", since the agent of change is external.

One official said: "SBM is a municipality-initiated project, there was pressure, not a real pressure, but efforts were made, there were differences in the importance of this project, made me suspect that there were other objectives. "When I asked him, what do you mean by" other goals", he spoke in general and said there were rumors about intentions to Israeli the Palestinian educational system in Jerusalem, but I am not sure."

\section{Lack of Members Training}

(administrative staff): "All I have learned from this course is" nihul 'atsmi", the Hebrew term for" autonomous management. "I find it hard to pronounce the Hebrew term and it is the word most frequently heard in the meeting."

Another teacher: "I felt a change; it is related to the character of the principal." SBM is positive because he explains so many vague things that I did not know in the past.

It is possible to indicate, on the basis of the results presented in the first question, that the concept of SBM is complex and complicated. Their first understanding of the concept is that through SBM, they will have absolute freedom in the operation of their school since the project is a corrective, up-to-date and advanced program. Thus, it is natural to have a positive attitude towards it. On the other hand, there are reservations about their capacity for implementation in the light 
of the cultural, political and social context of the Palestinian schools in Jerusalem.

As for the second question: how do teachers see SBM in the context of decision-making?

\section{Lack of Decision Making}

Several participants agreed that the decision-making mechanism is still in the hands of the supervisor and the second principal. Despite the majority's assertion that SBM grants to the general authorities, they indicate that these authorities are only limited to the financial aspect and do not touch other educational problems. The majority say that the initiatives come from the administration, ministry or supervisor.

This was emphasized by a member of the administrative staff who stated:

"Grade 6 teachers discussed the graduation ceremony and set the date and time. Two weeks before graduation, we were surprised neither to find that the principal changed the date without informing us nor even to consult us.

Another teacher (administrative staff), "the fifth-grade teachers agreed to take a trip to Lake Tiberias, but the principal decided that the trip would be towards an amusement park."

It is noticed that the decision-making mechanism and the freedom invested in the team is not there because the principal is still the decision-maker and there is no possibility of flexibility to delegate the authorities to other bodies, other administrative staff.

The Ministry's recent movement in 2015/2016 to increase the number of school supervisors (5 new supervisors) aims to eliminate SBM from its importance and direct it towards centralization rather than decentralization. This issue was confirmed during the discussions with the majority of principals and the organizational advisor, especially when new supervisors are appointed at this particular stage, it is considered an indicator of centralization.

On the third question: how does administrative staff describe SBM in the context of educational programs and curricula?

\section{The Political Context-Curricula-Context}

$16 / 25$ argues that there is a clear policy to modify or modify the curriculum according to the Israeli curriculum. The majority says they do not believe that the purpose of introducing SBM is to Israeli curriculum, but it helps. The majority of schools after SBM are colored with Israeli colors. One staff member indicated that he had decided to develop an extracurricular plan to visit deserted villages such as Lifta to talk about the disaster of his residence, but the travel coordinator insisted that there will be no political questions, precisely there a denial of reality and a concentration on geographical landmarks.

Interviews were also found that the Ministry of Education in Jerusalem is speeding up the process of review and modification of the program. A member of the administrative staff stressed that "we are not allowed to directly buy textbooks from the Palestinian Ministry of Education. The Ministry and the municipality are responsible for purchasing textbooks, modifying them and distributing them in schools. "

Another principal added: "Due to the procedures for revising, modifying and removing all nationalist content, the municipality is delaying the distribution of textbooks and it can take weeks. As a result, many parents do not wait and make direct purchases of textbooks from the PNA without any modification, so that their children can catch up with classroom instruction.

An administrative staffer added, "Once a supervisor has visited the school and seen a manual without any modification or deletion, he asked us to replace it with a modified manual."

As for the fourth question: how does the administrative staff describe SBM from the financial point of view?

5/5 Directors agreed unanimously that SBM offers independence in the treatment of resources, including financial resources. This has significantly reduced bureaucracy, especially with regard to the purchase of school supplies. On the other hand, many, especially the administrative staff, do not know how to deal with the budget, as this involves complicated calculations. The department and the municipality have put us in a critical situation and we are held accountable. For example, one director said that the message to them was: "It's up to you now; you decide what you want and it is best to have priorities."

Another director said: "I am pleased with this project and the elimination of the bureaucracy. However, the budget allocated is not large enough. Our schools in East Jerusalem require renovation and construction. It costs a lot of money. SBM's allocated budget does not cover this aspect. Sometimes I feel frustrated buying a computer from SBM funds or renovating a room or playground. This is not the case with SBM. " 


\section{Conclusion and Recommendations}

This research clearly demonstrates the extent to which cultural and socio-political factors impact in SBM school in East Jerusalem. The SBM model is intended to greatly reduce tension between central such as curriculum planning and curriculum planning at the level of the level of the individual school.

The study determined that despite their SBM designation, the central Ministry of Education maintains control of the Arab education schools in East Jerusalem. This policy enables the government to control the schools, precludes the introduction of any content that may be perceived as politically "incedaiary" and fosters a "culture of silence" that avoids and potential conflict with central authority.

The characteristics of Arab Palestinian culture also come into play in this situation. There is real fear of introducing external cultural influences.

A follower of the results of this project in the world concludes that the project has succeeded in some countries such as Australia and New Zealand (Caldwell, 2012) since the evaluation matrix for this project is a democracy that is financially supported, so it gives a greater space of independence to the school especially in the bureaucracy. On the other hand, the context of our research is the absence of the democratic matrix because there is no independence of decisions in a bureaucracy in a busy and poor society.

The results indicated that the general attitude of the administrative staff is positive. From a theoretical point of view, the majority is in favor of the school authorities being able to manage the school's operations independently. Administrative staff, however, raises doubts and concerns about the ability to apply this model to a range of contradictions and different cultural and social contexts under occupation.

Administrative staff explained that there were initial understanding and acceptance of the project, but the more they deepen the project, the more they face enormous difficulties. Most of the documents on SBM are in Hebrew, and many members do not know the language. In addition, several participants indicated that the SBM update course was short and insufficient to cover all aspects of SBM. In addition, contradictions in the instructions given by the Ministry and the Municipality raise many doubts about SBM.

It should be noted that the main objective of SBM is to grant school authorities the freedom to make decisions. The ministry and the municipality issued instructions, regulations, and decisions without consulting the school and its administration. This may negatively reflect staff and increase their fears and doubts about the importance and feasibility of the project.

The main question that raises the doubts of the administrative staff is the extracurricular activity. Many believe that the Palestinian training program is weak. (UNRWA, 2008) indicated that the program is weak and described it as being overdue and unable to follow the dialogue because of the isolation of the dominant power's knowledge.

As for (UNRWA 2008), they asserted that this is a traditional academic program of information. It confirms facts and information but neglects the skills of thinking and problem-solving. As a result, the municipality is trying to change the program based on this claim. What is revealed from the point of view of the administrative staff is that examination, modification, and suppression did not address these educational problems; in fact, they were Palestinian, nationalist and patriotic texts. This, in and of itself, created doubts as to the real intentions of the project, that it is not a development and recovery program, but rather a project that contributes to the Israelisation of programs and privatization of schools.

Undoubtedly, SBM has contributed to bringing about a successful change, especially in rich Western societies, but has widened the gap between poor and rich schools in some countries, as is the case in Israel.

Jerusalem schools that live under occupation and have no clear vision and objectives are destined to fail in this project. The question asked is why do we need SBM now in these schools? It's an open question. However, the primary findings of this research provide partial answers as to whether the project is more focused on the Israeli or school privatization than on effective school management. Therefore, we recommend the following:

1. Before the implementation of SBM, there should be a full preparatory year for participants to familiarize themselves with the project.

2. The school should have the freedom to choose to participate in the program or not.

3. All materials related to this project should be translated into Arabic to allow for better introduction, familiarization, and knowledge of the project.

4. Palestinian schools in Jerusalem should have financial independence in the management of their affairs, provided that the curriculum management remains Palestinian and provided that the Palestinian National Authority radically modifies these programs, especially in the areas of thought, problem-solving and student aid develops dialogue skills. 
5. It is difficult to offer a large project in a society that is under occupation. It would be better to improve the infrastructure.

6. Schools should be supervised by organizational advisors who speak Arabic and are able to understand the social and cultural context of Palestinian society in Jerusalem.

- This research sponsor by Bethlehem University

\section{References:}

Auhtor (2005), (2009), (2012), (2016)

Besley, T., \& Ghatak, M. (2003). Incentives, choice, and responsibility in the delivery of public services, Oxford Review of Economic Policy, 19(2), 235-249. https://doi.org/10.1093/oxrep/19.2.235

Bogdan, R. C., \& Biklem, S. K. (1998). Qualitative research in education: An introduction to theory and methods, (3rd ed) Needham heights, ma: Allyn a bacon

Caldwell, B, (2012). School based management in Arab school in an international context, Leading and Management, 18(2), 92-108.

Caldwell, B. (1988). The self-managing school (London: Falmer).

Caldwell, B. (2005). School management, educational policy series. Unesco international Academy of education and international Institute for educational planning.

Cheng, Y. (2000). Educational change and development in the Asia-pacific region: Challenges for the future, 317-344.

Cobbold, T. (2012). School autonomy is not the success demanded by education brief. Retrieved from http//www.saveourschools.com.au

Emmanuel, D. (1996). How to improve curriculum planning in schools, Jerusalem: ministry of education (in Hebrew)

Friedman, I., Barman, R., \& Toren, S. (1997, 2001). Level of self-management in the school (Jerusalem: Henrietta Szold Institute press in Hebrew).

Gazel, H. (2003). School management, theory, research and practices (University of Tel Aviv, Ramot press in Hebrew).

Gaziel, H., Bogler, R., \& Nir, A. E. (2005). Implementation of school management in schools. An evaluation of inhibitors and catalysts. Report to the office of the chief scientist (Israeli ministry of education), Knesset research and information center (2010) Israel

Macbeth, J. (2009). Recruitment and retention of senior leaders: meeting the challenge, European education research, $8(3), 407-417$.

Manchi (2011-12). Education alamance, distribution of classes and students in east Jerusalem by type of educational framework, the website of the Jerusalem municipality.

Mizel, O. (2005). School management in Bedouin schools in Israel, unpublished doctoral thesis (University of Leicester).

Mizel, O. \& Caldwell, B., (2012). School management in Arab schools in an international context, Leading and Managing, 18(2), 92-108.

Mizel, O. (2011). Curriculum development in Israeli primary schools, language, culture and school curricula and isolated isotopes, 24(2).

Nir, A. (2001). Development aspects of school management schools (Jerusalem: Institute for the research of educational culture, Hebrew university press).

Nusibeh, R. (2013). Educational Exclusion under an ethnocratic state. The case of East Jerusalem, Durham University

Rabin, Y. (2002). The Right to Education (Tel-Aviv, Nero Publishing (in Hebrew)

Report of the state comptroller (2008) Israel

Said, O. (2008). School management, Cairo, dar eman (Arabic)

Schleicher, A. (2004). I resultti dell'italia nell'indagine overview of ocse education '(Paris: oecd). Power point available at <www.oecd.org/data.oecd/33/33/33732967.ppt)

Shavelson, R. (1987). An indicator system for the follow-up of the teaching of mathematics and sciences, Santa Monica. California

Taub Institute statistical yearbook (2015) Israel

UNRWA (2008). Education Report, online. 
Volansky, A., \& Bar-Eli, A. (1995). Moving towards equitable school based management, Educational Leadership, 4(53), 60-62.

Whitty, G., Power, S. Et al. (1998). Development and choice in education. School, state, and market. Buckingham: open University press.

Wobmann, L. (2001). Why Students in some countries do better: international evidence on the importance of education policy x, Education Matters, 1(2), 67-74.

\section{Copyrights}

Copyright for this article is retained by the author(s), with first publication rights granted to the journal.

This is an open-access article distributed under the terms and conditions of the Creative Commons Attribution license which permits unrestricted use, distribution, and reproduction in any medium, provided the original work is properly cited. 